\title{
Tribological Properties of the Journal Bearings Used in Tamping Unit of Railways Tamping Machines
}

\author{
Ersin ÇAKIR, Recai Fatih TUNAY*
}

\begin{abstract}
A tamping machine is a machine used to pack the track ballast under railway tracks to make the tracks more durable. As well as being faster, more accurate, more efficient and less labour-intensive, tamping machines are essential for the use of concrete sleepers since they are too heavy to be lifted by hand. Tamping machines, also correct the alignment of the rails to make them parallel and level, in order to achieve a more comfortable ride for passengers and freight and to reduce the mechanical strain applied to the rails by passing trains. In this study, tribological properties of CuSn14 tin bronze used journal bearing system in aggregate of tamping machine were examined experimentally at different speeds and loads. Pin-on disc test apparatus was used for experiments. Experiments have been conducted so as to be able to determine the tribological properties in the event of using CuAl10Fe5Ni5 aluminum bronze considered as an alternative instead of tin bronze. The obtained results were compared with each other.
\end{abstract}

Keywords: aluminum bronze; friction; tin bronze; wear

\section{INTRODUCTION}

Transportation systems are the tools having an active role in the reviving of the social and cultural and particularly economic activities of a country. For this reason, the fertile use of the natural resources, rapid distribution of the goods and services, development of the domestic and foreign trade will only be possible with the careful planning of transportation and forming a regular transportation network [1]. Railways have a significant importance among the transportation activities in terms of functionality, economy and safety. The railway transportation being in use for approximately two hundred years shows significant developments day by day all over the world in terms of safety, comfort and speed and it gives way to technological renovations. Today, the transportation realized fast, safely, comfortably and in peace is accepted as an important indicator of the development and economic power [2, 3]. Physical and parametric distortions occur in the railway line structures with the impacts of many factors such as frost, drawdown, the structure and characteristics of the soil, train speed and the number of trains passing. These problems are removed with the line maintenance processes performed from the tamping process to the complete line renewal with the use of measurement processes with empirical methods [4]. The railway machines show usage differences depending on the new line construction, line renewal and the operations of maintenance works; and machine selection is made according to the process to be made. The materials used in the railway lines are the track failure detection machines, track renewal machines, ballast tamping machine, ballast regulator, ballast ramming and line stabilizer and the tamping machines. The road safety decreases with the accidents stemming from the insufficiency of maintenance and renewal and the absence of regular work schedules and it causes significant material damages [5]. The tamping machines used in the railway line construction and repair are used in the removal of the horizontal and vertical eccentricity of the rails and to provide the complete fit of the rails with the ground (Fig. 1).

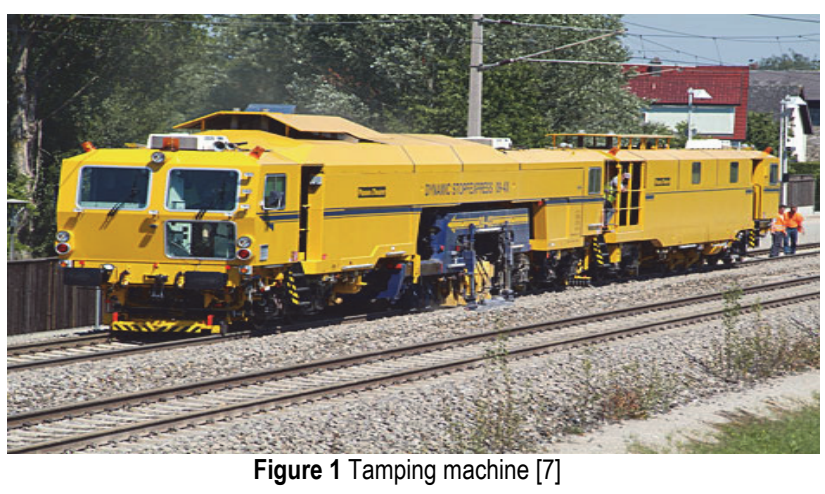

The tamping machines work on four principles. These are: to provide vertical and horizontal support, keep the rails in a single level and help dressage [6]. Tamping machine is a kind of special engineering equipment used in the railway construction. The aggregate unit shown in Fig. 2 is the part that is compressing the ballast in the tamping machines. This part works on two main processes: compression and vibration. While ballast is compressed under the traverses during compression, the vibration movement applies pressure [8].

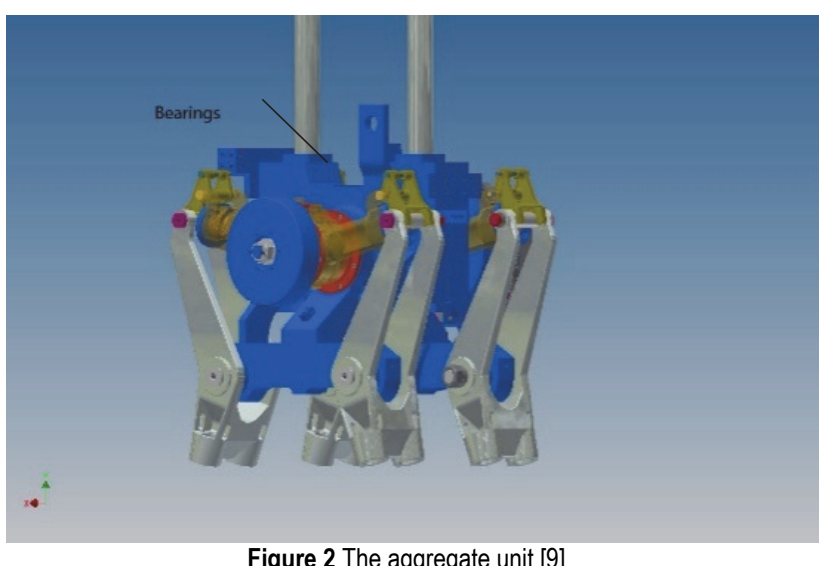

The industrial tamping aggregate consists of chassis, fixation shaft (colon shaft), eccentric shaft, support arms, compression forks (handles), dowel and hydraulic 
cylinder [10, 11]. ISO VG 100 oil is used for lubrication in this machine's hydraulic system.

In this study, tribological properties of CuSn14 Tin Bronze used journal bearing system in aggregate of tamping machine were examined experimentally at different speeds and loads. Pin-on disc test apparatus was used for experiments. After, CuAl10Fe5Ni5 Aluminum bronze was used instead of CuSn14 Tin Bronze and the experiments were repeated. In recent years, many studies have been performed to investigate the tribological performance of the $\mathrm{Cu}$ and $\mathrm{Al}$ alloys [12-19]. Singh et al, investigated the wear and friction behaviour of copperbased hybrid composites in dry sliding conditions using pin-on-disc tribometer at variable normal load, constant sliding speed and sliding distance. In their studies, hybrid composites showed low wear characterization compared to the copper matrix; particularly $\left(\mathrm{WC}+\mathrm{Al}_{2} \mathrm{O}_{3}+\mathrm{Cr}\right.$ ) hybrid reinforced composites revealed better wear resistance among all [12]. Joswik describes the tribological wear as the wear of machine part elements resulting from friction that causes changes in the weight, structure and physical properties of the surface layer in the contact areas [13]. Sarkar et al., determined the hardness, tensile properties and wear with coefficient of friction (COF) behaviour of all these austempered specimens. Wear test is carried out with sliding speed of $1.86 \mathrm{~m} / \mathrm{s}$. They stated that the wear was related to the friction coefficient behavior [16].

\section{EXPERIMENTAL PROCEDURE}

The bearings used in the fixation of the aggregate arms to the body and movement in tamping machines are the copper-based material alloys. In the conducted study, the tribological properties of the tin bronze $\mathrm{Br} 3(\mathrm{CuSn} 14)$ material and SAE8620 steel bushing working together on the machine in the pin on disc experiment apparatus have been examined and additionally, experiments have been conducted so as to be able to determine the tribological properties in the event of using $\mathrm{Br} 11(\mathrm{CuAl10Fe} 5 \mathrm{Ni5})$ Aluminum bronze considered as an alternative instead of tin bronze. The bearing systems used on the tamping machines are shown in Fig. 3.

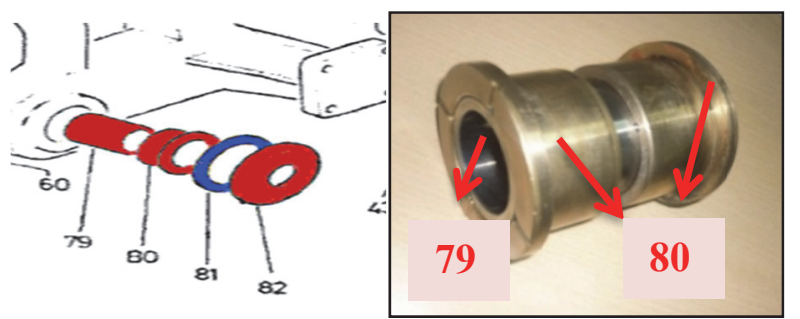

Figure 3 The bearing systems used on the tamping machines. (79) Steel bushing and (80) bronze journal bearing [9]

The disc material prepared for the purpose of using in pin on disc experiment set is the alloyed steel SAE8620 and the materials of the pins to be tested are CuSn14 (DIN1705) and CuAl10Fe5Ni5 (DIN1714) alloys in sequence. The disc and pin samples used in the experiments are seen in Fig. 4. The diameter of the pin is $13 \mathrm{~mm}$. The chemical compositions of the pins are given in Tab. 1 and Tab. 2.

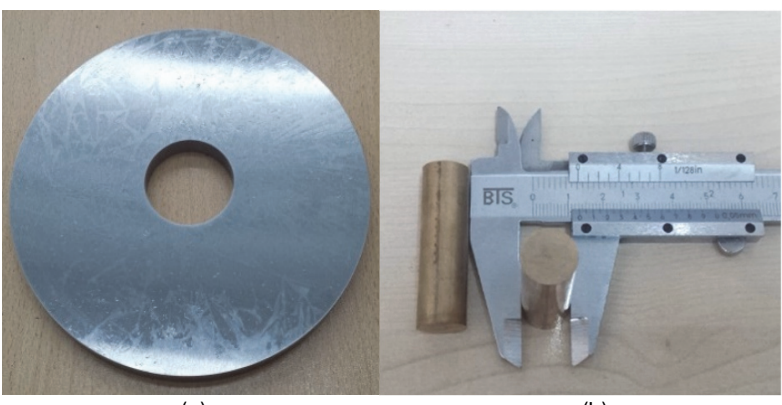

(a)

Figure 4 (a) Disc; (b) pins [9]

Table 1 The chemical compositions (wt. \%) of the CuSn14 pins [9]

\begin{tabular}{|c|c|c|c|}
\hline Element & $\mathbf{\%}$ & Element & $\mathbf{\%}$ \\
\hline $\mathrm{Sn}$ & 13,90 & $\mathrm{P}$ & 0,05 \\
\hline $\mathrm{Zn}$ & 0,40 & $\mathrm{Mn}$ & -- \\
\hline $\mathrm{Pb}$ & 0,45 & $\mathrm{Al}$ & -- \\
\hline $\mathrm{Ni}$ & 0,40 & $\mathrm{Cu}$ & Bal. \\
\hline $\mathrm{Fe}$ & 0,05 & & \\
\hline
\end{tabular}

Table 2 The chemical compositions (wt. \%) of the CuAl10Fe5Ni5 pins [9]

\begin{tabular}{|c|c|c|c|}
\hline Element & $\mathbf{\%}$ & Element & $\mathbf{\%}$ \\
\hline $\mathrm{Al}$ & 10,15 & $\mathrm{P}$ & 0,05 \\
\hline $\mathrm{Fe}$ & 4,95 & $\mathrm{Zn}$ & 0,05 \\
\hline $\mathrm{Mn}$ & 0,50 & $\mathrm{Sn}$ & 0,05 \\
\hline $\mathrm{Ni}$ & 5,10 & $\mathrm{Cu}$ & Bal. \\
\hline $\mathrm{Pb}$ & 0,05 & & \\
\hline
\end{tabular}

The hardness of disc is HRC55 \pm 2 , and average roughness is measured as $(R a) 0,70 \pm 0,02 \mu \mathrm{m}$. The average roughness $(R a)$ of pin materials is measured as $0,40-0,45 \pm 0,03 \mu \mathrm{m}$.

In the study, the wearing amounts have been determined with the mass loss method. For this reason, after the pins have been washed with Hexane both before and after the experiment and dried with hot air, their masses have been measured with the scale having the sensitivity of $0,0001 \mathrm{~g}$. In this study, the physical properties of the oil used to provide the hydrodynamic lubrication condition are given in Tab. 3 .

Table 3 The physical properties of the oil used in experiments [9]

\begin{tabular}{|c|c|}
\hline Kinematic viscosity $(\mathrm{cSt})$ & $\begin{array}{r}157,0\left(40^{\circ} \mathrm{C}\right) \\
19,0\left(100{ }^{\circ} \mathrm{C}\right)\end{array}$ \\
\hline Viscosity index & 137 \\
\hline Density $\left(15^{\circ} \mathrm{C}, \mathrm{kg} / \mathrm{l}\right)$ & 0,888 \\
\hline Flash point $\left({ }^{\circ} \mathrm{C}\right)$ & 215 \\
\hline Pour point $\left({ }^{\circ} \mathrm{C}\right)$ & -27 \\
\hline
\end{tabular}

The experiments have been carried out with the speeds of $250 \mathrm{rpm}, 500 \mathrm{rpm}$ and $750 \mathrm{rpm}$ in the loads of $25 \mathrm{~N}, 50 \mathrm{~N}$ and $75 \mathrm{~N}$ in ambient temperature under hydrodynamic lubrication conditions. 20W50 motor oil has been used as the lubricant. $5 \mathrm{~km}$ has been selected as the proceeding distance.

\section{RESULTS AND DISCUSSION \\ 3.1 Friction Coefficients of CuSn14 Bronze Journal Bearings}

When the graphics of friction coefficient drawn for the experiments conducted under the loads of $25 \mathrm{~N}, 50 \mathrm{~N}$ and $75 \mathrm{~N}$ are examined, it has been detected that with the increase in the speed, the friction coefficient increases, too (Figs. 5 to 7 ). 


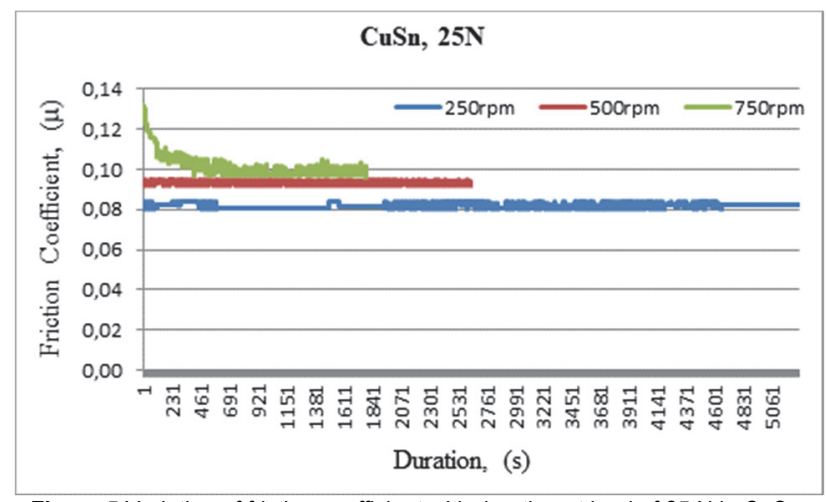

Figure 5 Variation of friction coefficient with duration at load of $25 \mathrm{~N}$ in CuSn bearings [9]

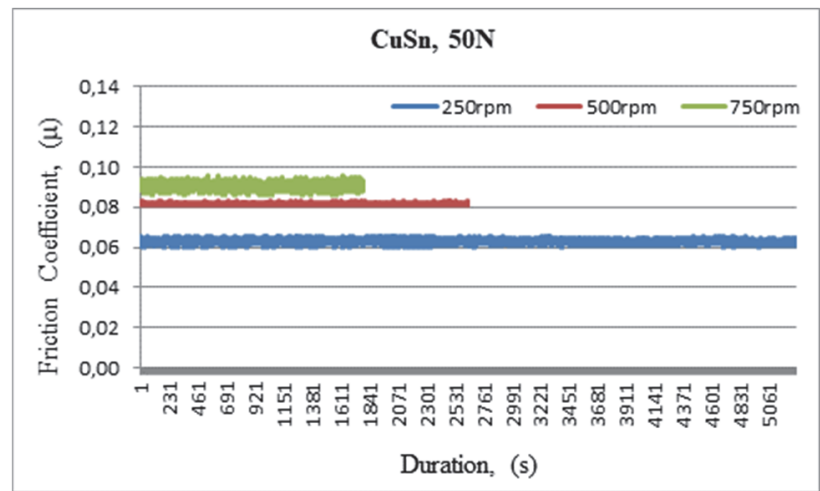

Figure 6 Variation of friction coefficient with duration at load of $50 \mathrm{~N}$ in CuSn bearings [9]

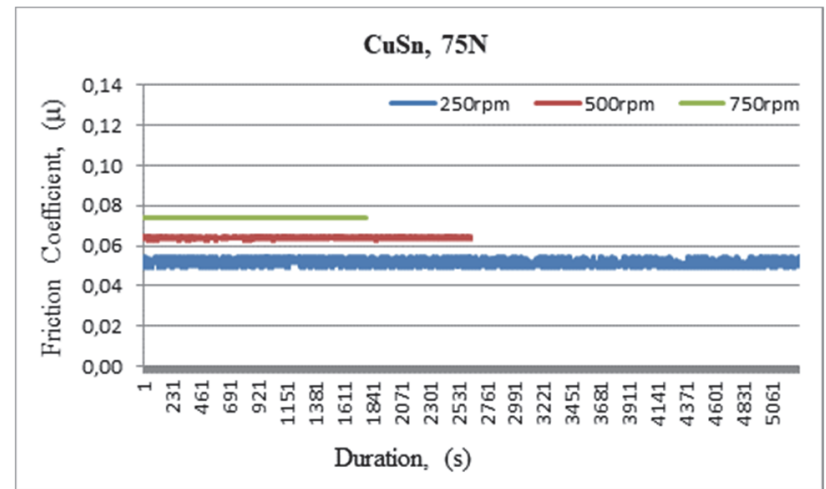

Figure 7 Variation of friction coefficient with duration at load of $75 \mathrm{~N}$ in CuSn bearings [9]

In the experiment conducted at the speed of $25 \mathrm{~N}, 750$ rpm, while the friction coefficient has been higher at the beginnings of the experiment, after a while, this value has become stabilized. This situation can be explained with the oil film not being formed completely at the beginning of the experiment.

When the attained values are examined, it has been detected that the average friction coefficients in the experiments conducted under $25 \mathrm{~N}$ load are 0,082 at the speed of $250 \mathrm{rpm}, 0,094$ at the speed of $500 \mathrm{rpm}$ and 0,102 at the speed of $750 \mathrm{rpm}$ (Fig. 5).

It has been detected that the average friction coefficients in the experiments conducted under $50 \mathrm{~N}$ load are 0,063 at the speed of $250 \mathrm{rpm}, 0,082$ at the speed of $500 \mathrm{rpm}$ and 0,091 at the speed of $750 \mathrm{rpm}$ (Fig. 6).

It has been detected that the average friction coefficients in the experiments conducted under $75 \mathrm{~N}$ load are 0,052 at the speed of $250 \mathrm{rpm}, 0,064$ at the speed of $500 \mathrm{rpm}$ and 0,074 at the speed of $750 \mathrm{rpm}$ (Fig. 7).

\subsection{Friction Coefficients of CuAl10Fe5Ni5 Bronze Journal Bearings}

When the friction coefficient graphics drawn for the experiments conducted under each three load are examined, it has been detected that the friction coefficient increases together with the increase in speed.

In the experiment conducted at the speed and load of $25 \mathrm{~N}, 250 \mathrm{rpm}$, while the friction coefficient has been higher at the beginnings of the experiment, after a while, this value has become stabilized. The friction coefficients have been detected averagely as 0,089 at $250 \mathrm{rpm}$ speed, 0,097 at $500 \mathrm{rpm}$ speed and 0,104 at $750 \mathrm{rpm}$ speed (Fig. 8).

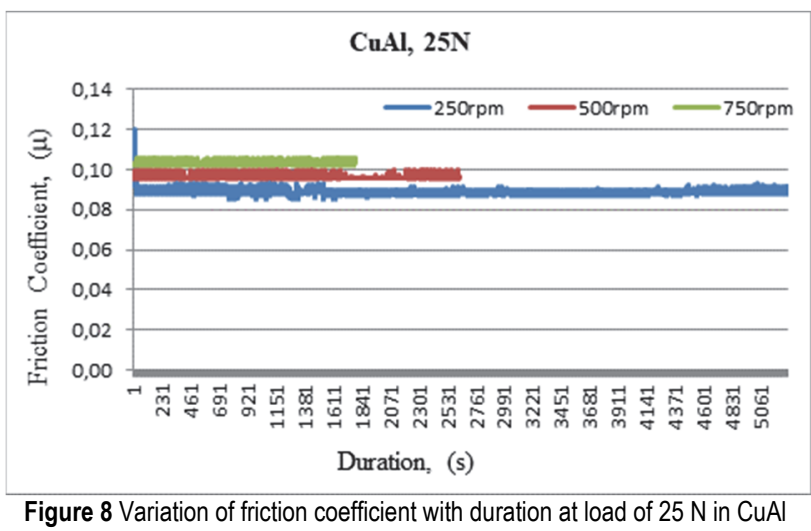
bearings [9]

It has been detected that the average friction coefficients in the experiments conducted under $50 \mathrm{~N}$ load are 0,066 at the speed of $250 \mathrm{rpm}, 0,085$ at the speed of $500 \mathrm{rpm}$ and 0,096 at the speed of $750 \mathrm{rpm}$ (Fig. 9).

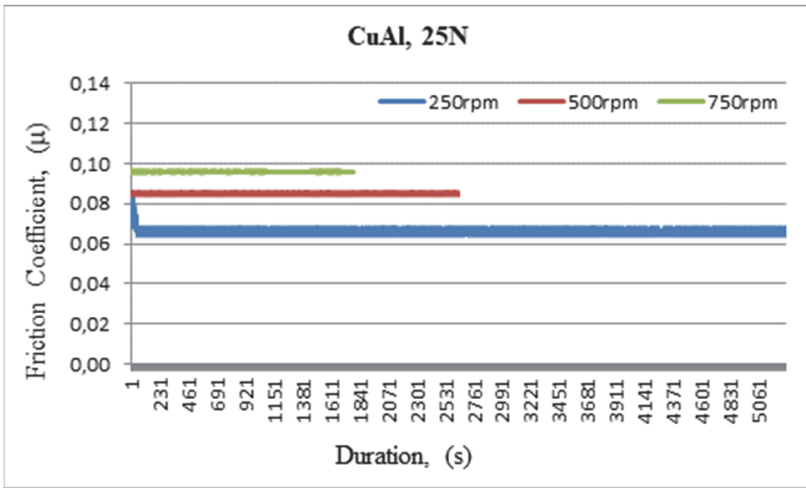

Figure 9 Variation of friction coefficient with duration at load of $50 \mathrm{~N}$ in CuAl bearings [9]

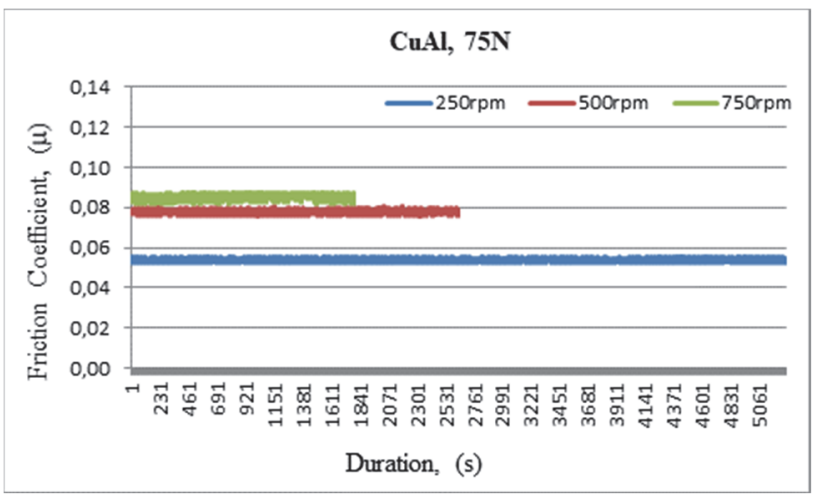

Figure10 Variation of friction coefficient with duration at load of $75 \mathrm{~N}$ in CuAl bearings [9] 
It has been detected that the average friction coefficients in the experiments conducted under $75 \mathrm{~N}$ load are 0,054 at the speed of $250 \mathrm{rpm}, 0,078$ at the speed of $500 \mathrm{rpm}$ and 0,085 at the speed of $750 \mathrm{rpm}$ (Fig. 10).

When the graphics are examined, it is seen that the friction coefficients of DIN1714 (CuAl) samples under all load and speed conditions are higher than the friction coefficients of DIN1705 (CuSn). It has been determined that the greatest difference between the friction coefficients of both of the sample groups has occurred in the experiments conducted under the conditions of $75 \mathrm{~N}$ load and $500 \mathrm{rpm}$. In the experiments conducted under 25 $\mathrm{N}$ and $750 \mathrm{rpm}$ conditions, while the friction coefficient of $\mathrm{CuSn}$ sample has been higher than that of $\mathrm{CuAl}$ sample, approximately after 7 minutes of the start of the experiment, it has continued to be lower than the friction coefficient of $\mathrm{CuAl}$ sample (Figs. 5 to 8).
The avarage friction coeffients for all test conditions are given Tab. 4 .

Table 4 Avarage friction coeffients [9]

\begin{tabular}{|c|c|c|c|c|c|c|}
\hline & \multicolumn{3}{|c|}{$\begin{array}{c}\text { DIN1705 } \\
\text { (CuSn14) }\end{array}$} & \multicolumn{2}{c|}{ DIN1714 (CuAl10Fe5Ni5) } \\
\cline { 2 - 7 } & $\begin{array}{c}\mathbf{2 5 0} \\
\text { rpm }\end{array}$ & $\begin{array}{c}\mathbf{5 0 0} \\
\text { rpm }\end{array}$ & $\begin{array}{c}\mathbf{7 5 0} \\
\text { rpm }\end{array}$ & $\begin{array}{c}\mathbf{2 5 0} \\
\text { rpm }\end{array}$ & $\begin{array}{c}\mathbf{5 0 0} \\
\text { rpm }\end{array}$ & $\begin{array}{c}\mathbf{7 5 0} \\
\text { rpm }\end{array}$ \\
\hline $\mathbf{2 5} \mathbf{~ N}$ & 0,082 & 0,094 & 0,102 & 0,089 & 0,097 & 0,104 \\
\hline $\mathbf{5 0} \mathbf{~ N}$ & 0,063 & 0,082 & 0,091 & 0,066 & 0,085 & 0,096 \\
\hline $\mathbf{7 5} \mathbf{~ N}$ & 0,052 & 0,064 & 0,074 & 0,054 & 0,078 & 0,085 \\
\hline
\end{tabular}

\subsection{Wear Test Results}

The CuSn and $\mathrm{CuAl}$ samples used in the experiments have been washed with Hexane liquid both before and after the experiment; they have been dried and weighed on the scale with the sensitivity of $0,0001 \pm 0,0002 \mathrm{~g}$. The wearing amounts attained as a result of the experiments are completely shown in Fig. 11.

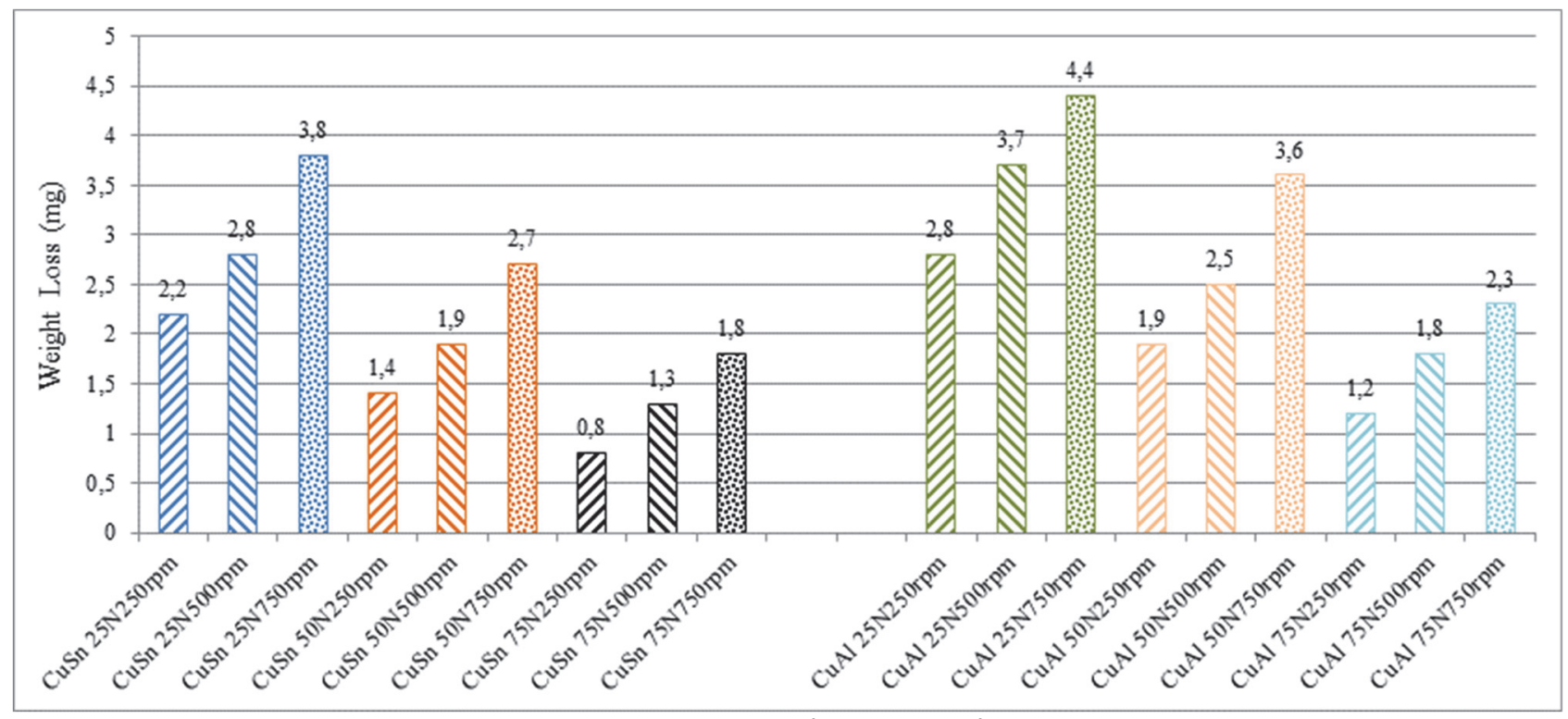

Figure 11 Weight loss of the tet samples [9]

When Fig. 11 is examined, it is seen that the values of friction coefficient given in Figs. 5 to 10 and the wearing amounts are in conformity. It has been detected that in the experiments conducted under the same conditions, the bronze bearings including tin have been worn less than the bearings including aluminum.

While the greatest wearing amount in $\mathrm{CuSn}$ bearings has been detected as $0,0038 \mathrm{~g}$ in the experiments conducted under the conditions of $25 \mathrm{~N}$ and $750 \mathrm{rpm}$, the lowest wearing amount has been attained as 0,0008 $\mathrm{g}$ in the experiments conducted under the conditions of $75 \mathrm{~N}$ and $250 \mathrm{rpm}$.

While the greatest wearing amount in $\mathrm{CuAl}$ bearings has been detected as $0,0044 \mathrm{~g}$ in the experiments conducted under the conditions of $25 \mathrm{~N}$ and $750 \mathrm{rpm}$, the lowest wearing amount has been attained as 0,0012 $\mathrm{g}$ in the experiments conducted under the conditions of $75 \mathrm{~N}$ and $250 \mathrm{rpm}$.

When both the friction coefficient graphics and the wearing graphics are examined together, it is seen that the tribological behaviors of the bronzes including tin have been higher than the tribological behaviors of the bronzes including aluminum.

- The hardness value of CuSn samples (HB115) is lower than that of $\mathrm{CuAl}$ samples (HB120) although it is little.

- The surface roughness values of both of group samples are the same because they have been subjected to the same sandpapering and polishing processes. In the measurements, the values of the surface roughness have been measured at the level of $0,40-0,45 \pm 0,02 \mu \mathrm{m}$ on average.

The sample hardnesses specified above and the surface roughnesses at the friction coefficient and the wearing amounts are examined together.

Although the hardness value of the aluminum bronze is a little higher than that of the tin bronze, the difference between them is not as big as to affect the friction coefficient and as a result, the wearing amount. It is considered that the lubricating property of the tin could easily tolerate this difference seen in the hardness value and therefore, the tin bronze shows better tribological performance than the aluminum bronze [20-22]. 
In the study conducted by Chen et al., 2014, aluminum has been added in the copper and the wearing experiments have been conducted under dry conditions. As a result of the experiments they have conducted, they have detected that the Aluminum added below 0,5\% decreases the wearing ratio and the aluminum amount added above this value increases the wearing ratio. They have detected the friction coefficient of around 0,7 on average in the study conducted under the conditions of 30 $\mathrm{N}$ and $5 \mathrm{~Hz}$. In the same study, they have also observed a decrease in the coefficient of friction while the speed increases.

Heide et al. 2006 conducted wearing tests with aluminum bronze (it included 15,2\% aluminum bronze in weight) and AISI304 stainless steel and they determined the conditions of the experiments as $100 \mathrm{~N}$ load, $0,5 \mathrm{~ms} / \mathrm{s}$ and $1500 \mathrm{~m}$ road. They carried out the experiments in oily environment and found that the friction coefficient as a result of the experiment ranged between 0,03-0,08. In addition, they observed that the surface roughnes values in their study decreased after the experiment.

The changes in the friction coefficients found in this study are in conformity with the literature when the right side of Stribeck curve, namely the friction zone is assessed by taking into consideration. The friction coefficient increases with the increase in the speed at the liquid part of Stribeck curve; and the friction coefficient decreases with the increase in the load. When the literature is examined, it is also thought that the values of the friction coefficient comply with the literature.

\subsection{Metallographic Examination}

Surface photographs of the samples used in the experiments have been taken both before and after the experiments with the help of optic microscope. The surface photographs taken before the experiments are given in Fig. 12.

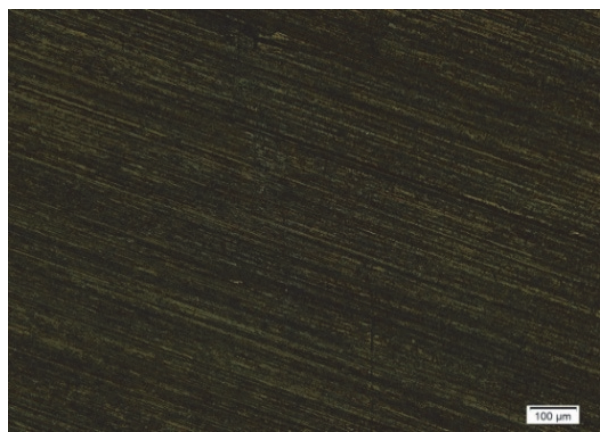

(a)

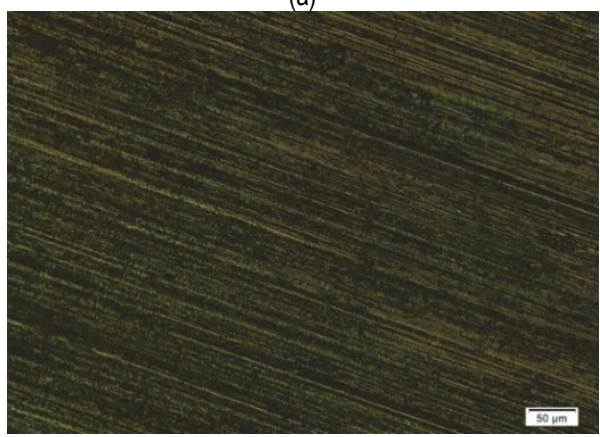

(b)

Figure 12 The surface photographs of CuSn samples before the experiments: (a) 100x; (b) 200x [9]
The conditions of experiment in which the mass loss is experienced as the most and the least have been preferred for both groups of samples in the photograph taking of the surface after the experiments. The experiment conditions in which the mass loss is the least for tin bronze (DIN 1705) are the conditions of $75 \mathrm{~N}$ and $250 \mathrm{rpm}$. The most mass loss for the same group of materials has occurred under the conditions of $25 \mathrm{~N}$ and $750 \mathrm{rpm}$. Fig. 13 shows the surface photographs taken under the conditions of experiment in which the most and the least mass loss has occurred for tin bronze samples.

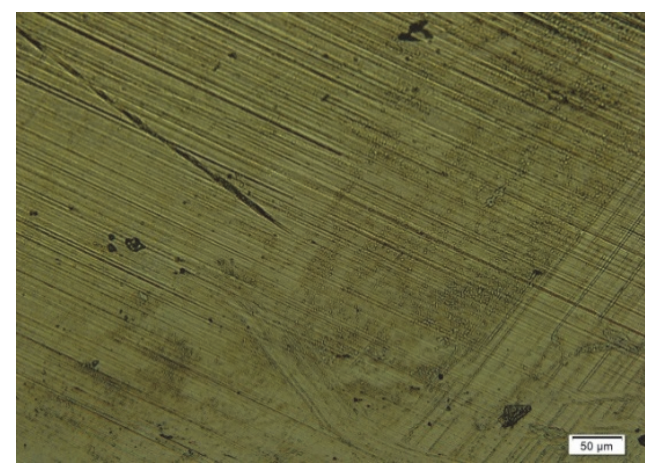

(a) $200 x$

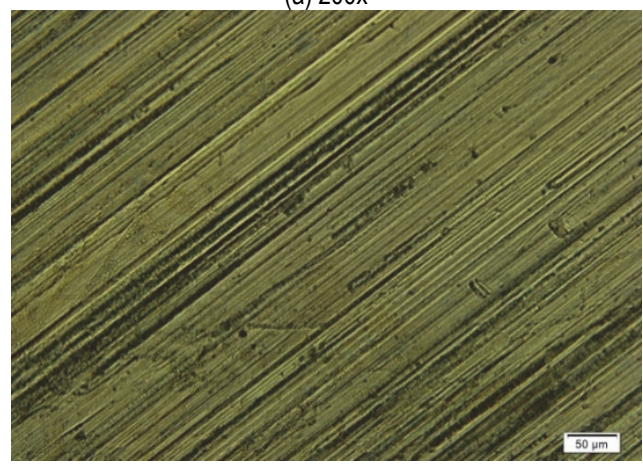

(b) $200 x$

Figure 13 The surface photographs for CuSn samples: (a) 75 N, 250 rpm; (b) $25 \mathrm{~N}, 750 \mathrm{rpm}[9]$

While the experiment conditions in which the mass loss has occurred as the least for aluminum bronze (DIN 1714) samples, have been the conditions of $75 \mathrm{~N}$ load and $250 \mathrm{rpm}$, the conditions in which the mass loss has been the highest are $25 \mathrm{~N}$ load and $750 \mathrm{rpm}$. Fig. 14 shows the surface photographs taken under the conditions of experiment in which the most and the least mass loss have occurred for aluminum bronze samples.

As a result of the metalographic examinations, it has been observed in both of the material groups that on the surfaces, the brightness has increased when compared to the surfaces before using. It is considered that the roughness peaks on the surface have broken as a result of contacting with each other and the surfaces have been seen as brighter due to the impact of sandpapering. In addition, it has been understood that the traces seen in all of the surfaces are the wearing traces and these traces remind of the fact that the abrasive wearing has occurred.In his study, Can investigated the wear behavior of cold worked CuSn5-Steel Bimetallic materials experimentally. He carried out his studies on pin-in-ring type experiment set under dry conditions. He stated that the wear resistance of the ballised bushings was found to be considerably higher than that of the non-ballised bushings. He stated that the 
type of wear occurring in his study was abrasive wear. In this study, similar results have been obtained.

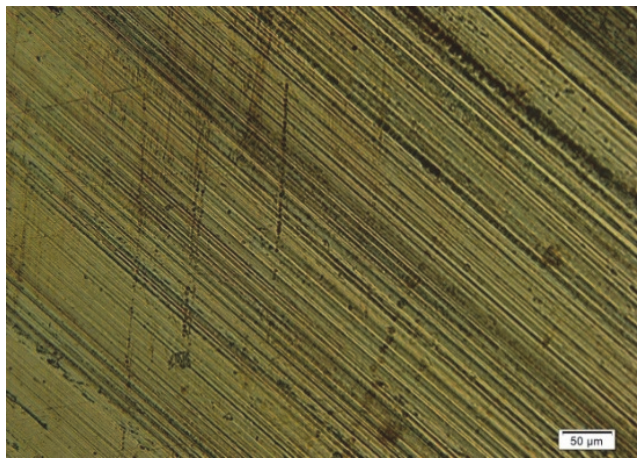

(a) $200 x$

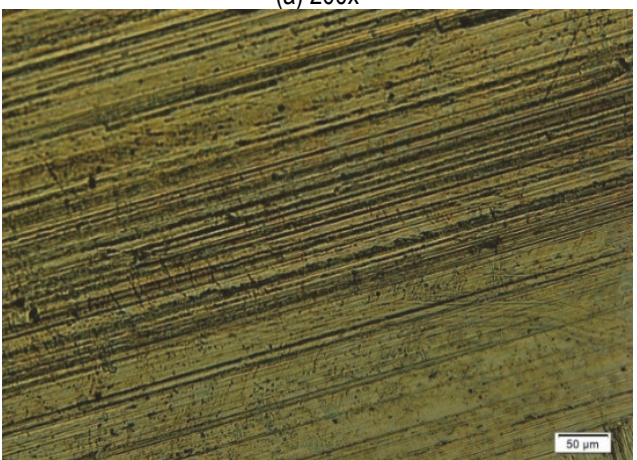

(b) $200 x$

Figure 14 The surface photographs for CuAl samples: (a) 75 N, 250 rpm; (b) $25 \mathrm{~N}, 750$ rpm [9]

When Figs. 13 and 14 are examined, in the samples in which the wearing amount is great, more and deeper wearing traces have been detected. The wearing traces are more visible in the aluminum bronzes when compared to those of the tin bronzes and this image is also in convenience with the wearing amounts.

Opalic et al. stated that by reducing the friction coefficient in plain bearings, various advantages such as low loss, low energy consumption, low temperature during operation and less amount of fluid required for lubrication can be revealed.

\section{CONCLUSIONS}

For the purpose of being able to determine the tribbological properties of DIN1705 (CuSn) and DIN1714 (CuAl) samples, the following results have been attained in the experiments conducted under three different loads and three different speeds under the conditions of Pin on disc experiment device, ambient temperature and hydrodynamic lubrication.

1. It has been detected that in all samples, the friction coefficients have increased with the increase in the speed under the same load.

2. When the experiment speed is kept constant, it has been detected that the friction coefficient has decreased with the increase in the load.

While the highest friction coefficient in DIN1705 samples has been found as 0,102 under the conditions of $25 \mathrm{~N}$ load and $750 \mathrm{rpm}$ speed, the lowest friction coefficient has been detected as 0,052 under the conditions of $75 \mathrm{~N}$ load and $250 \mathrm{rpm}$ speed.
While the highest friction coefficient in DIN1714 samples has been found as 0,104 under the conditions of $25 \mathrm{~N}$ load and $750 \mathrm{rpm}$ speed, the lowest friction coefficient has been detected as 0,054 under the conditions of $75 \mathrm{~N}$ load and $250 \mathrm{rpm}$ speed.

3. When the wearing experiment results are examined, it has been determined that the wearing amounts occurring in DIN1714 samples are higher than the wearing amounts occurring in DIN1705 samples. This result is also in convenience with the friction coefficients.

When all the attained results are assessed together, it is concluded that the friction coefficient of CuSn bronze and the wearing amounts are lower than those of bronzes including Aluminum. Together with this, it is also seen that the difference between them is close to each other under the same conditions. As a result of the experiments conducted, it can be said that the bearings including aluminum can be considered as an alternative bearing material in the Railway Tamping Machines Aggregate unit under suitable lubrication conditions and suitable loads and speeds.

The tribological properties of the DIN1714 $(\mathrm{CuAl})$ bearings considered to be used have been both examined under dynamic loads and their fatigue behaviors have been detected; and it is considered that more comprehensive results related to the use of these bearings can also be attained.

In addition, with the application of the suitable surface processes (such as covering, forming bi-metal), it can also be taken into consideration that the wearing behaviors of the bearings can be enhanced.

\section{Acknowledgement}

The authors would like to acknowledge the financial support (Project No. 3707-YL1-13) by the Scientific Research Coordination Department of Süleyman Demirel University.

\section{REFERENCES}

[1] Akgüngör, A. P. \& Demirel, A. (2004). Analysis of the transportation system and transportation policy in Turkey. Pamukkale University Journal of the Engineering Science, 10(3), 423-430.

[2] Altınok, S. (2001). Transport policy in Turkey, comparison of highways and railways. Selcuk University Faculty of Economics and Administrative Sciences, The Journal of Social and Economic Research (ISSN:2148-3043), 73-87.

[3] Cheng, W. (2006). A Retrospect of the development of mechanical equipments for railway maintenance in China. Modern Management, 10(4), 181-182.

[4] Rhayma, N., Bressolette, Ph., Breul, P., Fogli, M., \& Saussine, G. (2013). Reliabilty Analysis of maintenance operations for railway tracks. Reliability Engineering and System Safety, 114, 12-25. https://doi.org/10.1016/j.ress.2012.12.007

[5] Güler, H. \& Evren, G. (2006). Modeling railway track geometry deterioration: Information systems based study. ITU Journal/d (Journal of Istanbul Technical University), 5(3), 205-214.

[6] See http://www.evra.org.uk/engineering

[7] See http://www.plasser.com.au/en/p_mainline_tamping/ 094x.htm 
[8] Liu, Y., Gong, G., \& Min, C. (2013). Present status and prospect of tamping device exciting technology. Journal of Mechanical Engineering, 49(16), 138-146. https://doi.org/10.3901/JME.2013.16.138

[9] Çakır, E., (2014). Experimental investigation of tribological properties of the journal bearings using in tamping unit of railways tamping machines, Master Thesis. Suleyman Demirel University.

[10] Zhou, T., Hu, B., Yan, B., \& Sun, J. (2013). Experimental and numerical study of railway ballast compactness during tamping process. Advanced Materials Research, 690-693, $2730-2733$ https://doi.org/10.4028/www.scientific.net/AMR.690-693.2730

[11] Zhou, T., Hu, B., Sun, J., \& Liu, Z. (2013). Discrete element metod simulation of railway ballast compactness during tamping process. The Open Electrical \& Electronic Engineering Journal, 7, 103-109. https://doi.org/10.2174/1874129001307010103

[12] Singh, M. K. \& Gautam, R. K. (2019). Dry sliding friction and wear behaviour of developed copper metal matrix hybrid composites. International Journal of Surface Science and Engineering, 13(2/3),133-155. https://doi.org/10.1504/IJSURFSE.2019.102362

[13] Joswik, J. (2018). Evaluation of tribological properties and condition of Ti6Al4V titanium alloy surface. Technical Gazette, 25(Suppl. 1), 170-175. https://doi.org/10.17559/TV-20160521145125

[14] Shen, M. X., Cai, Z. B., Mo, J. L., Peng, X. D., \& Zhu, M. H. (2015). Local fatigue and wear behaviours of 7075 aluminum alloy induced by rotational fretting wear. International Journal of Surface Science and Engineering, 9(6),520-537. https://doi.org/ 10.1504/IJSURFSE.2015.072833.

[15] Purcek, G., Yanar, H., Shangina, D. V., Demirtas M., Bochvar, N. R., \& Dobatkin, S. V. (2018). Influence of high pressure torsion-induced grain refinement and subsequent aging on tribological properties of $\mathrm{Cu}-\mathrm{Cr}-\mathrm{Zr}$ alloy. Journal of Alloys and Compounds, 742, 325-333. https://doi.org/10.1016/j.jallcom.2018.01.303

[16] Sarkar, T., Bose, P. K., \& Sutradhar, G. (2017). Mechanical and tribological characteristics of copper alloyed austempered gray cast iron (AGI). Materials Today: Proceedings, 5, 3664-3673.

[17] Lin, Y. C., Chen, J. N., Huang, Y. C., \& Jian, Y. H. (2015). Wear and friction characteristics of surface-modified aluminium alloys. International Journal of Surface Science and Engineering, 9(2/3), 109-123. https://doi.org/ 10.1504/IJSURFSE.2015.068236

[18] Zhou, H., Yao P., Gong, T., Xiao Y., Zhang, Z., Zhao, L., Fan, K., \& Deng, M. (2019). Effects of $\mathrm{ZrO}_{2}$ crystal structure on the tribological properties of copper metal matrix composites. Tribology International, 138, 380-391. https://doi.org/10.1016/j.triboint.2019.06.005

[19] Ashwath, P., Jeyapandiarajan, P., Xavior, M. A., Somani, M., Dharnia U., \& Grover, H. (2018). Effect of copper alloying and reinforcement percentage on the microstructure-tribological aspects of the aluminium alloy composites. Materials Today: Proceedings, 5, 1185311858. https://doi.org/10.1016/j.matpr.2018.02.156

[20] Backensto, A. B. (1990). Effects of lubricants on the properties of copper-tin powders and compacts, advances in P/M. Proc. of PM Conference N. Jersey, 303-314.

[21] Schmidt, R. F. \& Schmidt, D. G. (1993). Selection and application of copper alloy castings. ASM Handbook (II), 346-355.

[22] Prasad, B. K. (1997). Dry sliding wear response of some bearing alloys as influenced by the nature of micro constituents and sliding conditions. Metall Trans, (A-28), 809-815. https://doi.org/10.1007/s11661-997-1008-3
[23] Chen, X., Han, Z., \& Lu, K. (2014). Wear mechanism transition dominated by subsurface recrystallization structure in $\mathrm{Cu}-\mathrm{Al}$ alloys. Wear, 320, 41-50. https://doi.org/10.1016/j.wear.2014.08.010

[24] Heide, E. V. D, Stama, E. D., Giraud, H., Lovatob, G., Akdut, N., Clarysse, F., Caenen, P., \& Heikill, I. (2006). Wear of aluminum bronze in sliding contact with lubricated stainless steel sheet material. Wear, 261, 68-73. https://doi.org/10.1016/j.wear.2005.09.023

[25] Can, A. (2016). Effect of the ballising process on wear behaviour of CuSn5-steel bimetal bushings. Journal of the Balkan Tribological Association, 22(4A-I), 4495-4506.

[26] Opalić, M., Domitran, Z, \& Katana, B. (2014). Comparison of antifriction properties of polymer composites and bronze. Tehnički Vjesnik, 21(5), 1089-1095.

\section{Contact information:}

\section{Ersin CAKIR}

Provincial Directorate of Trade, Ministry of Customs and Trade, 65000 Van/Turkey

E-mail: ersincak@gmail.com

Recai Fatih TUNAY, PhD, Associate Professor (Corresponding Author)

Department of Mechanical Engineering,

Faculty of Engineering,

University of Suleyman Demirel,

32260 Isparta/Turkey

E-mail: recaitunay@sdu.edu.tr 